\title{
latrogenic neck mobility restriction due to stereotactic fixed-frame application: Implications of a 'non-laryngoscopic' airway management approach
}

\author{
Rachna Bhutani, Amitabh Dutta, Neelam Ganguly, Jayashree Sood
}

\begin{abstract}
Stereotactic biopsy is a common minimal access neurosurgical procedure. It requires a stereotactic frame to be secured on the head, and thereafter, based on computerised tomography scan markings on the frame, precise biopsy is retrieved. For anaesthesiologists, the application of frame poses difficulty in accessing the upper airway with the conventional laryngoscopy-intubation methodology. The various airway-access limitations imposed by an 'in-place' frame can be problematic and should be addressed. This report elucidates the problems caused by the presence of stereotactic frame in the management of upper airway. The approach to upper airway can be variable on a case-to-case basis, depending on attending anaesthesiologists' decision-making and availability of equipments/devices. Here, the, recommendations on the problematic points and the suggested way thereof are presented.
\end{abstract}

Key words: Stereotactic frame, supra glottic airway, tracheal tube exchanger

\section{INTRODUCTION}

Stereotactic neurosurgery has its own share of anaesthetic implications, including those related to upper airway management. ${ }^{[1,2]}$ Primarily, the application of the stereotactic frame results in a difficult-to-access airway situation due to induced neck movement limitation and difficulty with the conduct of direct laryngoscopy. ${ }^{[3]}$ We present an anticipated non-difficult airway whose management became problematic due to the presence of an in-position stereotactic frame. The difficulties with

Departments of Anaesthesiology, Pain and Perioperative Medicine, Sir Ganga Ram Hospital, New Delhi, India

Address for correspondence:

Dr. Rachna Bhutani, Department of Anaesthesiology,

Pain and Perioperative Medicine, Sir Ganga Ram Hospital,

New Delhi - 110 060, India.

E-mail: rachnabhutani@ymail.com

\begin{tabular}{|l|l|}
\hline \multicolumn{2}{|c|}{ Access this article online } \\
\hline Quick Response Code: & Website: \\
\hline & www.jnaccjournal.org \\
\cline { 2 - 2 } & \\
\hline & \\
\hline
\end{tabular}

upper airway access and approach to circumvent them are presented.

\section{CASE REPORT}

A 46-year-old obese female $(160 \mathrm{~cm}, 102 \mathrm{~kg})$ was scheduled for stereotactic biopsy from the right occipital space-occupying lesion. With the exception of a short neck [Figure 1], the pre-operative airway examination was unremarkable. As per surgeon's decision, stereotactic frame was to be applied to patient's head under local anaesthesia followed by localisation by computerised tomography (CT)-imaging facilitated markings. The stereotactic biopsy was planned with the patient in 'prone' position under general anaesthesia.

The patient was transferred to operation room (OR) with stereotactic frame in position. Standard monitoring was applied, and venous access patency was ensured.

This is an open access article distributed under the terms of the Creative Commons Attribution-NonCommercial-ShareAlike 3.0 License, which allows others to remix, tweak, and build upon the work non-commercially, as long as the author is credited and the new creations are licensed under the identical terms.

For reprints contact: reprints@medknow.com

How to cite this article: Bhutani R, Dutta A, Ganguly N, Sood J. latrogenic neck mobility restriction due to stereotactic fixed-frame application: Implications of a 'non-laryngoscopic' airway management approach. J Neuroanaesthesiol Crit Care 2017;4:175-7. 


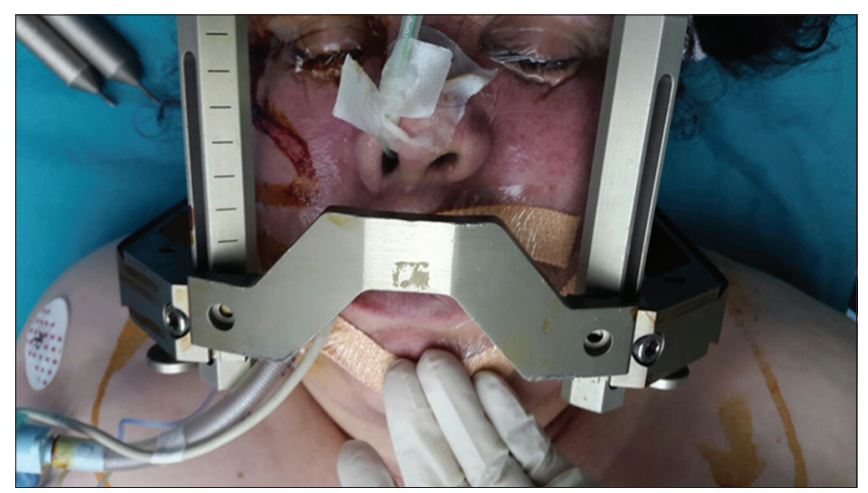

Figure 1: Patient applied with stereotactic frame

Intravenous ranitidine (50 mg), glycopyrrolate $(0.2 \mathrm{mg})$, and fentanyl $(2 \mathrm{mcg} / \mathrm{kg})$ were administrated before induction of anaesthesia. In view of the anticipated airway difficulty due to stereotactic frame in position, including restricted head-and-neck mobility, problem in performing direct laryngoscopy (the frame over the face limited laryngoscopic manipulation), and the requirement of tracheal tube (the patient was to be placed prone); a 'non-laryngoscopic' airway access approach was planned. After pre-oxygenation, anaesthesia was induced with propofol $(120 \mathrm{mg})$. An intubating laryngeal mask airway (ILMA number 3) was placed on the first attempt and adequacy of seal pressure ensured. Thereafter, when a dedicated tube $(7.0 \mathrm{~mm}$ ID) placed through ILMA failed to enter the trachea on repeated attempts, a fibre-optic bronchoscope (FOB, S. No. 1321605 LF-2, flexible fibrescope, Olympus, Tokyo, Japan) was utilised to facilitate tracheal intubation through the existent ILMA conduit. However, we encountered difficulty in removing the ILMA over the tracheal tube. Since the head and neck was fixed in a relative fixed-flexion position by in-place stereotactic frame, forcible retrieval of the ILMA over tracheal tube was fraught with risk of inadvertent extubation. Neither active removal of the ILMA was attempted (to avoid tracheal tube displacement) nor was FOB assistance for removal considered (possibility of damage to endoscope's delicate optical fibres). Oxygenation was continued through the ILMA tube. To overcome the difficulty, a pre-marked tracheal tube exchanger (TTE) was inserted through the ILMA tube up to the tip. Then, the ILMA along with the silicon tube was removed together over the TTE uneventfully. The ILMA tracheal tube was then railroaded over the TTE back into tracheal position and secured. All the above airway manoeuvres were performed under continuous intravenous propofol anaesthesia without any neuromuscular blockade. During the entire airway management sequence that lasted 12-min, patients' haemodynamics (heart rate, non-invasive blood pressure), oxygenation, and ventilation indices were maintained. Throughout the duration of airway management, the surgeons stood standby for removing the stereotactic frame, and if required, to undertake emergency surgical tracheostomy.

\section{DISCUSSION}

In our case, ILMA was considered upfront under a 'non-laryngoscopy' airway access plan to overcome airway difficulty posed by stereotactic frame in place. The stereotactic frame resulted in fixed-flexion 'head-and-neck' orientation thereby precluding the component of neck extension required to facilitate direct laryngoscopy-intubation. Furthermore, the frame significantly limited the plane through which the attending anaesthesiologist (standing at patients' head-end) approaches to perform laryngoscopy. Although the preformed right-angled shape of ILMA facilitated its placement with minimal force and/or manipulation, ${ }^{[4]}$ a clear possibility of loss of control emerged while retrieving it over the tracheal tube placed through its lumen. To ensure greater safety, a TTE ${ }^{[5]}$ was therefore utilised to gain flexibility and two-way control (removal and replacement of ILMA tracheal tube).

Alternatively, the airway access could well have been secured before stereotactic frame application. This was desirable but has its own set of issues, such as transporting an intubated patient if OR and CT facility are separate; unnecessary anaesthesia if there is a delay between tumour marking and stereotactic biopsy procedure, potential injury during shifting onto OR table, etc.

There are situations where other than the patient's own upper airway metrics, the dominant presence of a surgical frame required for facilitation of stereotactic biopsy makes options to access the airway difficult/complex. The presence of a stereotactic frame induces active loss of control over one or more of the conventional upper airway management manoeuvres required for completing the routine process of direct laryngoscopy-tracheal intubation, such that a non-difficult upper airway may also become difficult to access.

\section{CONCLUSION}

To ensure safety for patients awaiting stereotactic biopsy with a frame already in position, proactive identification of acquired difficulty in the airway management; ${ }^{[5]}$ strategy to select the most appropriate 'airway' devices (supra/infra-glottic airway); $;^{[2]}$ and combination 'approach' (conventional, guided) should be ensured. The use of various intubation 'aids' (FOB, tracheal tube introducers) should be judicially exercised 
to secure upper airway by a 'non-laryngoscopic' approach.

\section{Declaration of patient consent}

The authors certify that they have obtained all appropriate patient consent forms. In the form the patient has given her consent for her images and other clinical information to be reported in the journal. The patients understand that their names and initials will not be published and due efforts will be made to conceal their identity, but anonymity cannot be guaranteed.

\section{Financial support and sponsorship}

Department of Anaesthesiology, Pain and Perioperative Medicine, Sir Ganga Ram Hospital, New Delhi.

\section{Conflicts of interest}

There are no conflicts of interest.

\section{REFERENCES}

1. Bhade MA, Shah B, Dave CR, Shah RA. Anaesthetic aspects of stereotactic brain biopsy. Indian J Anaesth 2002;46:111-4.

2. Kurnutala LN, Kinthala S, Padmaja D. Emergency tracheal intubation through intubating laryngeal mask airway in patients with stereotactic frame in situ. Indian $\mathrm{J}$ Anaesth 2015;59:253-4.

3. George C, Ramesh V, Gangadharan JL, Konar SK. Airway management during anesthesia for stereotactic placement of intratumoral drug delivery system in a patient with anaplastic astrocytoma. J Anaesthesiol Clin Pharmacol 2012;28:129-30.

4. Fukutome T, Amaha K, Nakazawa K, Kawamura T, Noguchi H. Tracheal intubation through the intubating laryngeal mask airway (LMA-Fastrach) in patients with difficult airways. Anaesth Intensive Care 1998;26:387-91.

5. Apfelbaum JL, Hagberg CA, Caplan RA, Blitt CD, Connis RT, Nickinovich DG, et al. Practice guidelines for management of the difficult airway: An updated report by the American Society of Anesthesiologists Task Force on Management of the Difficult Airway. Anesthesiology 2013;118:251-70. 